\title{
Energy Threshold-based Cluster Head Rotation for Routing Protocol in Wireless Sensor Networks
}

\author{
Hadi Raheem Ali Hussein Attia Lafta \\ Department of Software, University of Babylon, Babil, Iraq \\ Itech.hadi@gmail.com \\ am.2222@yahoo.com
}

Keywords: WSNs, Single hop, multi-hop, unequal clustering, routing protocol

\begin{abstract}
Energy efficiency represents a fundamental issue in WSNs, since the network lifetime period entirely depends on the energy of sensor nodes, which are usually battery-operated. In this article, an unequal clustering-based routing protocol has been suggested, where parameters of energy, distance, and density are involved in the cluster head election. Besides, the sizes of clusters are unequal according to distance, energy, and density. Furthermore, the cluster heads are not changed every round unless the residual energy reaches a specific threshold of energy. The outcomes of the conducted simulation confirmed that the performance of the suggested protocol achieves improvement in energy efficiency.
\end{abstract}

\section{INTRODUCTION}

Definitely, Wireless sensor networks (WSNs) have been a significant field as a result of their increasing utilization in different applications. For example, WSN applications appear in areas of military operations, medical services, borders protection, disaster management, precaution maintenance, surveillance systems, and so on[1] [2]. Usually, WSN made up of a vast number of small-size and low-price devices called sensor nodes (SNs), which have the ability to work cooperatively for gathering information related to the self-interested environment.

Normally, the hardware of wireless sensor node is consisted of four main parts which are the sensing unit, the processing unit, the communication unit, and energy unit which is usually a battery cell. However, the resources of sensor nodes are constrained for different reasons such as cost, size, energy, bandwidth, radio range. On top of these constraints, the energy which represents a big matter that requires to be wisely tackled when designing WSN systems. So, to reduce energy consumption in WSNs, different algorithms of protocols have been introduced. The primary target of those protocols is to manage energy dissipation in WSN so that the network lifetime becomes longer.

In WSNs, routing the data consumes the most available energy compared to other operations, so adopting an efficient routing protocol becomes a 
necessary task. The protocols of routing in WSNs can be classified regarding the network nature into flat-based protocols, hierarchical-based protocols, and location-based protocols [3] [4]. In flat-based protocols, nodes equipped with similar capabilities and share the same functionalities[5]. Whereas, in the hierarchical-based routing such as clustering-based protocols, nodes can work either as a cluster member for sensing function or as a cluster head $(\mathrm{CH})$ so as to forwarding data to the base station [4]. While in location-based, routing protocols require position information about the destination, and this may require embedding a GPS device in each node [6]. Also, routing protocols can be categorized depending on their operating style into Query-based, QoS-based, negotiation-based protocols, Coherent-based, and non-Coherent-based protocols [5].

Generally, clustering-based routing protocols have been more suitable to conserve energy in WSNs, especially in large-scale networks. In that concern, there are many merits that clustering technique advocates for WSNs, such as it can distribute the workload among the network nodes evenly, reduce the overhead of communication traffic, provide scalability and help to avoid collisions in transmissions[7].

In clustering technique, Figure-1, nodes are subdivided into sets named clusters. Usually, each cluster consists of a certain number of sensing nodes named cluster members (CMs) that do sensing in the surrounding environment and a node with particular features takes the role as a cluster head. Besides, the job of cluster head is to gather data from cluster nodes and do the aggregation on that data before it sent to the base station (BS).

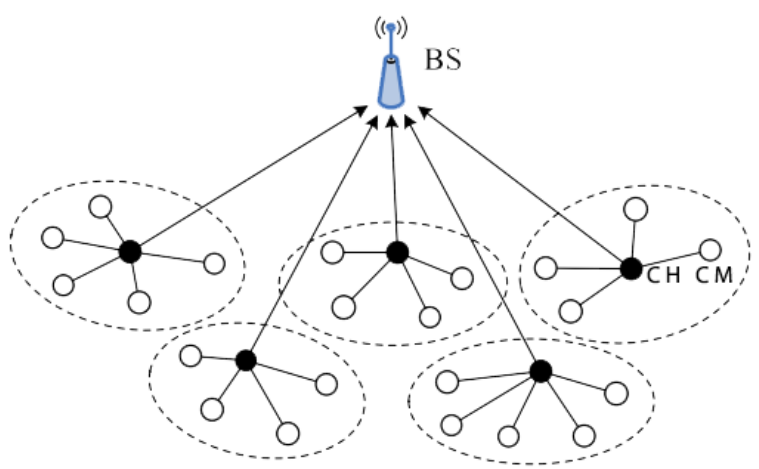

Figure-1: Clustering-Based Routing in WSNs

In most clustering-based routing protocol algorithms, there are a specific number of phases such as setup, data transmission, and clustering topology maintenance. The adopted techniques for each phase can play a crucial effect on the rate of energy expenditure. In this paper, an efficient clustering technique has been proposed in order to decrease energy dissipation and thus increasing the network lifespan.

The next topics of this article come as follows. The Section II shows some related work. Then, the proposed protocol explained in Section III. Afterward, a simulation for the suggested protocol and other protocols is introduced in 
Section VI. While in Section V, a discussion about the simulation results appears there. Last, in Section VI, the paper terminated with a concise conclusion.

\section{RELATED WORK}

Due to the impact of data routing on WSN's lifetime, different routing protocols have been proposed. Below are some of clustering-based routing protocols which are designed to manage energy dissipation so as to increase the network lifetime.

In [8], LEACH is introduced to be the first attempt of using clustering for constructing WSN's nodes. The protocol provides the advantage of rotating cluster head role among the nodes so as to prevent a premature death of individual nodes. Also, it is considered as a distributed protocol where the process of selecting cluster heads and forming clusters are done in a distributed manner. Typically, the protocol includes two parts, namely the setup phase and the steady-state phase. During the former phase, each node makes the decision of being a cluster head via taking a number in $[0,1]$ randomly and checking if it is lower than the threshold stated in equation (1), it will be a cluster head.

$$
T(n)=\left\{\begin{array}{cc}
P /\left(1-P *\left(r \bmod \left(\frac{1}{P}\right)\right) ;\right. & \text { if } n \in G \\
0 ; & \text { otherwise }
\end{array}\right.
$$

In the above equation, $T(n)$ represents the threshold of the current round, $P$ a predefined ratio of cluster heads per round, $r$ is the number of current round, whereas $G$ represents the non-cluster head nodes of the current epoch. While in the steady-state phase, the interesting information is collected from nodes by cluster heads, which aggregate and convey them to the BS in a single hop. Although LEACH made enhancement regarding network lifetime, it failed in some aspects such as follows. First, the residual energy does not consider in the cluster head selection process and thus may lead to selecting a node with little energy. Second, the distribution of cluster heads is not even in the network area, and this makes remote nodes expending more energy for communicating data. Third, nodes are not fairly assigned to cluster heads.

In [9], a distributed protocol called EECS which uses a single hop routing was proposed. In this protocol, the selection of cluster head starts by choosing a particular number of nodes as candidate cluster head nodes according to a predefined probability. After that, candidates that located within a predefined communication range, competing to be a final cluster head. Besides, the sizes of clusters in EECS are unequal depending on the distance. In that concern, the nearest cluster is the larger size with more members, and the far away one is the smaller with fewer members. Furthermore, the joining of plain nodes considers a weighted cost function, stated in equation (2), which takes into account the distance between the node and the cluster head as well as the distance between 
the cluster head and the BS. Therefore, each node joins to the least cost cluster head, and this reduces the workload on remote cluster heads besides reducing the total energy consumption.

$$
\operatorname{cost}(j, i)=w * f\left(d\left(S_{j}, C H_{i}\right)+(1-w) * g\left(d\left(C H_{i}, B S\right)\right.\right.
$$

In the previous equation, $w$ is a weighting factor within the interval $[0,1], i$ and $j$ are the indices of the stated node and cluster head respectively. Whereas, the sub-functions $f$ and $g$ are calculated as follows.

$$
\begin{aligned}
& f=\frac{d\left(S_{j}, C H_{i}\right)}{d_{f_{-} \max }} ; \text { where } d_{f_{-} \max }=\operatorname{EX}\left(\max \left\{d\left(S_{j}, C H_{i}\right)\right\}\right) \\
& g=\frac{d\left(S_{j}, C H_{i}\right)-d_{g_{-} \min }}{d_{g_{-} \max }-d_{g_{-} \min }} \quad ; \text { where } d_{g_{-} \max }=\max \left\{d\left(C H_{i}, B S\right)\right\} \\
& d_{g_{\_} \text {min }}=\min \left\{d\left(C H_{i}, B S\right)\right\}
\end{aligned}
$$

Regarding equation (2), the sub-function $f$ tends to make the node joining the nearest cluster head, whereas, the sub-function $g$ tends to make the node joining to the cluster head with less span from the BS. However, the decision of nodes joining to clusters according to the cost function made a considerable improvement in energy efficiency.

In [10], EEUC protocol aims to solve the problem of hot spots, when a multi-hop model of routing applied. In this protocol, nodes are organized into unequal-size clusters. So, clusters located next to the base station are small, while the further ones are large. Therefore, cluster heads near to the base station have more ability to conserve some energy so as to forward frequently incoming data packets. Besides, EEUC uses an energy-efficient algorithm to route data among cluster heads until the BS. So, each cluster head can convey data to the BS in two methods. First, when the cluster head located within a predefined threshold distance, defined as TD-MAX, from the BS, data transmitted in a single hop. Second, if the distance to the BS is larger than the TD_MAX, the current cluster head selects the next $\mathrm{CH}$ node of the more residual energy and less cost link according to the equation (3). In this equation, $d^{2}$ represents the Euclidian distance, and $\mathrm{CHi}$ and $\mathrm{CH}$ are the existing cluster head and the next cluster head respectively

$$
d^{2}(\operatorname{link})=d^{2}(C H i, C H j)+d^{2}(C H j, B S)
$$

The aim of EEDUC protocol [11] is to solve the hot-spot problem and balance energy dissipation across the network. In EEDUC, all sensor nodes participate in the competition of being $\mathrm{CH}$. In $\mathrm{CH}$ selection, the competition is based on a waiting time that considers the remaining energy and node degree, as 
shown in equation (4) and equation (5). Equation (4) is used to calculate the waiting time for nodes in the first round, since the initial energy of all nodes is equal, whereas the second equation (5) is used for the second round and above.

$$
w t_{i}=\left[(1-\alpha) * N_{i} / N_{M A X}\right]+[\alpha * V r]
$$

Where:

$N_{i}, N_{M A X}$ : the node's neighbours and the number of network nodes

$V r:$ a random number between 0.9 and 1

$\alpha$ : a constant value between 0 and 1

$$
w t_{i}=\left[(1-\beta-\gamma) * N_{i} / N_{M A X}\right]+\left[\beta * E_{i} / E_{M A X}\right]+[\gamma * V r]
$$

Where:

$E_{i}, E_{M A X}:$ are the residual energy of node and the initial energy

$\beta, \gamma:$ are a constant coefficient within interval $[0,1]$.

Then, each elected $\mathrm{CH}$ node announces its advertisement message of being a $\mathrm{CH}$ to its neighbors which locate in its competition radius. The competition range of each node is already calculated using equation (6), by considering the distance to the BS, the residual energy, and the node degree. Finally, in cluster formation, nodes join to the nearest $\mathrm{CH}$.

$R_{\text {comp }}=\left[1-w 1\left(1-\frac{T S}{T S_{M A X}}\right)-w 2\left(1-\frac{E_{i}}{E_{M A X}}\right)-w 3 \frac{N_{i}}{N_{M A X}}\right] R_{M A X}$

Where:

$T S, T S_{M A X}$ : Are the node's distance to BS and the maximum distance to BS

$E_{i}, E_{M A X}$ : Are the residual energy of node and the maximum energy (initial energy)

$N_{i}, N_{M A X}:$ Are the node neighbours and the total number of nodes

$R_{M A X}$ : The maximum radius that can be given to the node

$\mathrm{w} 1, \mathrm{w} 2, \mathrm{w} 2$ : Are a constant coefficient with values between $\mathrm{o}$ and 1

A variant version of LEACH in [12] called Improved-LEACH that enhanced the process of cluster heads selection. Improved-LEACH uses an adaptive ondemand weighting function as stated in equation (7) for selecting cluster heads and constitutes unequal size clusters. In that context, each node randomly gets a number between 0 and 1 and compares it against the threshold of equation (7), in a similar way as in LEACH protocol, to examine its eligibility for being cluster head.

$$
T(i)=\left\{\frac{P}{\left(1-P *\left(r \bmod \left(\frac{1}{P}\right)\right)\right.} *\left(a \cdot \frac{E i}{E o}+(1-a) \cdot D c\right) ; i \in G\right.
$$


In the equation (7), $a \in[0,1]$ and the term ( $a . E i / E o)$ prevents a node with an inadequate energy from being a cluster head. While the term $((1-a) . D c)$ gives remote nodes from the base station a higher chance to work as a cluster head than the adjacent nodes. Also, $G$ represents the sensor nodes which have not been cluster heads yet.

However, to get more information and details about unequal clustering algorithms, the reader can refer to [13] [14].

\section{The Proposed Routing Protocol}

The proposed protocol aims to make the energy dissipation even among cluster heads by adopting unequal clustering-based algorithm and using an effective energy threshold to rotate the cluster head role. Besides, the protocol utilizes a single hop routing for transmitting data to the base station. Simply, the proposed protocol includes the following main phases: setup, data transmission, and re-clustering. These phases can be described as below.

\section{A-Setup Phase}

This phase includes three sub-phases which can be detailed as follows:

\section{1- Initialization Sub-phase:}

This sub-phase begins when the BS disseminates a START_MSG message to all sensor nodes. By receiving this message, nodes compute their distances to the base station using the strength of receiving signals. Also, every node $S_{i}$ calculates its density for a one hop range using equation (8).

$$
D(i)=\sum_{j=1}^{k} e^{-a\left\|S_{i-} S_{k}\right\|^{2}} ; \quad a=\frac{4}{r^{2}}
$$

Where:

$k:$ Represents the number of neighboring nodes;

$r$ : Represents a predefined radius

$\left\|S_{i-} S_{k}\right\|^{2}$ : Represents the Euclidean distance between the node $S_{i}$ and $S_{k}$.

Then, nodes use equation (9) to calculate their competition radii. So, each node can simply determine its competitive radius based on the criterion of energy, distance, and density. Thus, the radius of each node will differ from others according to the above parameters

$$
R_{i . c o m p}=\left[1-c 1\left(\frac{d\left(S_{i}, B S\right)-d_{\min }}{d_{\max }-d_{\min }}\right)-c 2\left(1-\frac{E_{\text {res }}}{E_{o}}\right)-c 3\left(\frac{D(i)}{D_{\max }}\right)\right] * R_{\text {Max }}^{o}
$$

Where:

$d\left(S_{i}, B S\right)$ :represents the distance from the current node to the base station

$d_{\text {min }}, d_{\text {max }}$ : Represent the minimum and maximum distances from the nodes to the BS.

$E_{r e s}, E_{o}$ : The node's residual and initial energy.

$D(i)$ : The density of node.

$D_{\max }$ : The maximum density.

$R_{\text {Max }}^{o}:$ A predefined maximum radius that can be given to a node,

$c 1, c 2$ and $c 3$ : Predefined coefficients and their values in $[0,1]$. 
Then, all nodes participate in the process of choosing cluster heads based on a weighting function that involves energy, distance, and density as determined by equation (10).

$$
W(i)=\alpha\left(\frac{E_{r e s}(i)}{E o}\right)+\beta\left(1-\frac{d_{\left(S_{i}, B S\right)}}{d_{\max }}\right)+\gamma\left(\frac{D(i)}{D_{\max }}\right)
$$

Where:

$D_{\max }$ : The maximum density that can be given to a node.

$\alpha, \beta$, and $\gamma$ : Predefined coefficients and their values in $[0,1]$.

For the first round, the energy threshold $\left(E_{T h r}\right)$ is equal to the initial energy of nodes $\left(E_{o}\right)$. While for the next rounds, the threshold will be calculated according to the equation (11):

$$
E_{T h r}=\frac{1}{\alpha m} \sum_{j=1}^{m} E_{r e s}(j)-e\left(d_{j-t o-B S} / d_{\max }\right)
$$

Where:

$\alpha$ : A constant value between 1 and 2 and in this work is 1.5 .

$m$ : Represents the count of cluster heads.

$E_{\text {res }}(j)$ : The residual energy of cluster head (j).

$e:$ A constant value between $O$ and 1 and here its value 0.5 .

$d_{j-t o-B S}$ : The distance from the cluster head $\mathrm{j}$ to the BS.

$d_{\max }$ : The maximum distance between nodes and the BS.

\section{2-Cluster Head Selection sub-phase:}

Consequently, after the initial parameters are calculated, each node has energy equal or above the energy threshold $\left(E_{T h r}\right)$ takes part in the competition of cluster head selection, and thus sends out an ADV_MSG message to its neighbors which are located within a double distance of its competition radius and this message includes $\{I D$, Weight $(i)\}$. By examining the weights of others, the node of the highest weight will announce to be a final $\mathrm{CH}$ and send out a FINAL_CH_MSG message with information \{ID, residual energy, radius, distance_to_bs $\}$ to other nodes. The nodes located within that cluster head's radius will give up their competition for being cluster heads and become plain nodes. This process continues until each node in the network becomes either a cluster head or a plain node.

\section{3-Cluster formation Sub-Phase:}

When the selection of cluster heads has completed, the plain nodes send JOIN_MSG messages to the nearest cluster head in order to constitute clusters. Thereafter, each cluster head sends a TDMA timetable to its members.

\section{B-Data Transmission Phase}

In this phase, each node uses its own dedicated time slot for data transmission. Simply, nodes route data to the associated cluster head in a single hop. Then, each cluster head aggregates and sends data towards the BS also in a single hop routing.

\section{C-Re-Clustering Phase}

At the end of each round, where data transmitted towards the base station, each cluster head should check its residual energy. According to that test, if the residual 
energy of all nodes is above or equal to a current threshold, then the phase of data transmission continues; otherwise, the decision of re-clustering is taken, and thus the setup phase will be repeated. More important, the energy threshold is changed whenever the clustering phase is implemented, and its value determined by equation (11).

\section{Simulation}

To examine the performance of the suggested protocol, a simulation was conducted. For the simulation requirements, the energy consumption model in [8] was used. In this model, to convey k-length bits of data packet from the source sensor node to the target sensor node, the transmitting node expends an amount of energy stated in equation (12). Where, $E_{\text {elec }}$ represents the amount of energy expended by the transmitter circuits and $E_{f s}$ and $E_{m p}$ are energy consumption models, which are required for the amplifier, and they are interchangeably used according to the type of the adopted channel.

$$
E_{T x}=\left\{\begin{array}{lc}
k E_{\text {elec }}+k E_{f S} d^{2} & \text { if } d<d_{o} \\
k E_{\text {elec }}+k E_{f s} d^{4} & \text { if } d \geq d_{o}
\end{array}\right.
$$

Whereas, to receive k-length bits of data from other node, the receptive node consuming an amount of energy as defined by equation (13).

$$
E_{R x}=k E_{\text {elec }}
$$

Eventually, since data are aggregated at the cluster head, so the equation (14) represents the energy consumed by $\mathrm{CH}$ to aggregate and transmit k-length data packet. The term $k E_{D A}$ represents the amount of energy to aggregate klength bits of data.

$$
E_{T x}= \begin{cases}k E_{\text {elec }}+k E_{D A}+k E_{f s} d^{2} & \text { if } d \leq d_{o} \\ k E_{\text {elec }}+k E_{D A}+k E_{m p} d^{4} & \text { if } d>d_{o}\end{cases}
$$

For simulation experiments, other parameters of the network are defined a priori. However, table-1 includes the required parameters and their values.

Table-1: Parameters of WSN Network Simulation

\begin{tabular}{|l|l|}
\hline \multicolumn{1}{|c|}{ Parameters } & \multicolumn{1}{c|}{ Values } \\
\hline Network dimension & 200 $\mathrm{m}^{*}$ 200 $\mathrm{m}$ \\
\hline Nodes & Scenario-1=200, Scenario-2=400 \\
\hline BS Location & $(100,250)$ \\
\hline Initial Energy & 2 Joule \\
\hline
\end{tabular}




\begin{tabular}{|l|l|}
\hline $\mathrm{P}($ ratio of CHs) & 0.05 \\
\hline$E_{\text {elec }}$ & $50 \mathrm{~nJ} / \mathrm{bit}$ \\
\hline$E_{D A}$ & $5 \mathrm{~nJ} / \mathrm{bit}$ \\
\hline$E_{\mathrm{fs}}$ & $10 \mathrm{pJ} /$ bit.m $^{2)}$ \\
\hline $\mathrm{E}_{\mathrm{mp}}$ & $0.0013 \mathrm{pJ} /\left(\mathrm{bit}^{4}\right)^{4}$ \\
\hline $\mathrm{d}_{\mathrm{o}}$ & $87 \mathrm{~m}$ \\
\hline Data packet & $4000 \mathrm{bit}$ \\
\hline
\end{tabular}

In addition to the energy consumption model and network parameters, there are a certain number of assumptions are important to be stated, such as:

-All sensor nodes of the network are homogenous.

-Nodes are randomly distributed across the network afield.

-Nodes have ability to control their power of transmission range.

-Nodes are static after their deployment.

-Nodes always have data ready to be sent periodically.

-A free of interference and collision environment is assumed.

-The channel access methods, TDMA and CSMA, are utilized for intra-cluster and inter-cluster communication respectively.

Figure-2 and figure-3 next, show the structure of the network and how the clusters are configured according to the propsed protocol. These figures also show the intra-cluster communications and inter-cluster communcations for data routing.

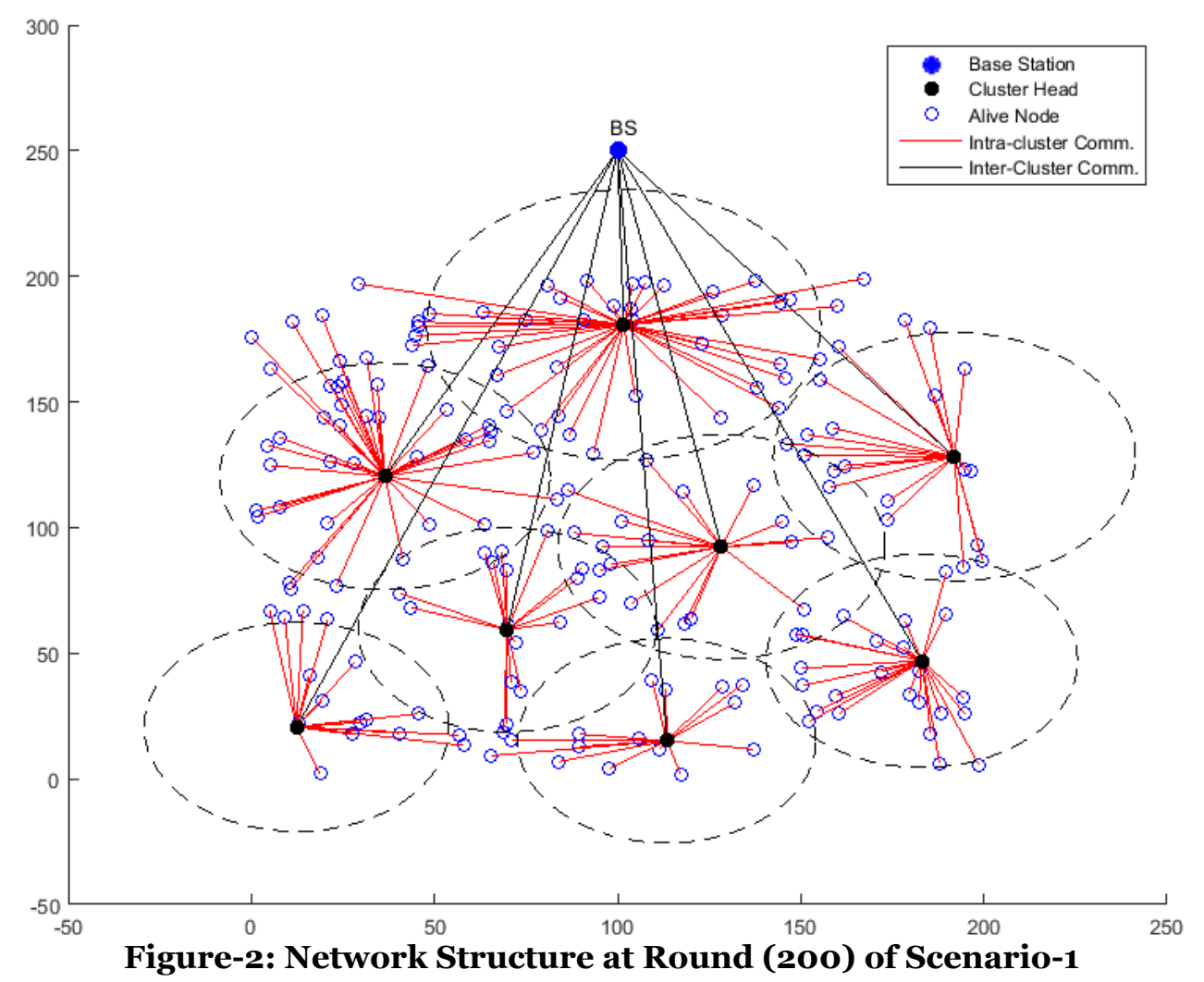




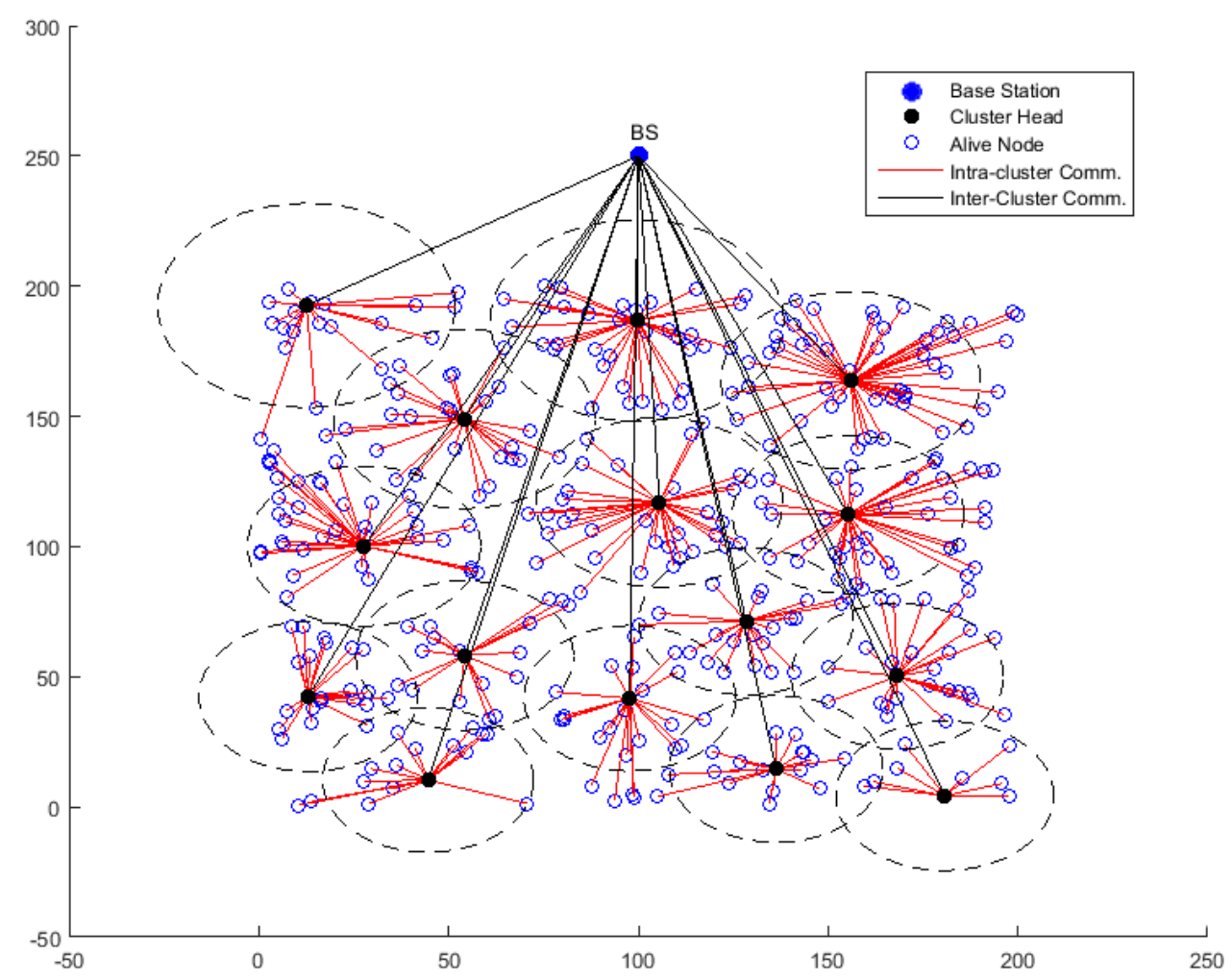

Figure-3: Network Structure at Round (200) of Scenario-2

\section{RESUlts AND Discussions}

For performance evaluation purposes, some performance measures such as the lifetime, throughput, energy consumption, and residual energy are used. The results stated in table-2 and table-3, show the network lifetime represented in rounds corresponding to the percentage of dead nodes for the simulated protocols: the proposed, LEACH and Improved-LEAH respectively. By examining these tables, it clearly shows that the improvement in the network lifetime for the proposed protocol over other simulated protocols.

Table-2: Network Lifetime for Simulated Protocols (Scenario-1)

\begin{tabular}{|c|c|c|c|c|c|}
\hline Scenario-1 & \multicolumn{2}{|c|}{ Network lifetime(Rounds) } & \multicolumn{2}{c|}{$\begin{array}{c}\text { of improvement } \\
\text { over }\end{array}$} \\
\hline $\begin{array}{c}\text { No. of dead } \\
\text { nodes }\end{array}$ & Proposed & LEACH & $\begin{array}{c}\text { I- } \\
\text { LEACH }\end{array}$ & LEACH & I-LEACH \\
\hline FND & 1825 & 1179 & 1381 & 54.79 & 32.15 \\
\hline $10 \%$ & 1957 & 1429 & 1643 & 36.95 & 19.11 \\
\hline $25 \%$ & 2114 & 1777 & 1916 & 18.96 & 10.33 \\
\hline HND & 3186 & 2728 & 2603 & 16.79 & 22.40 \\
\hline $75 \%$ & 3745 & 3425 & 3358 & 9.34 & 11.52 \\
\hline $90 \%$ & 4117 & 3791 & 4174 & 8.60 & -1.37 \\
\hline \multicolumn{7}{|c|}{ BS at (100,250), Area=200x200, Node=200, P=0.05 } \\
\hline
\end{tabular}

Table-3: Network Lifetime for Simulated Protocol(Scenario-2)

\begin{tabular}{|c|c|c|}
\hline Scenario-2 & Network lifetime(Rounds) & $\begin{array}{c}\text { \% of improvement } \\
\text { over }\end{array}$
\end{tabular}




\begin{tabular}{|c|c|c|c|c|c|}
\hline $\begin{array}{c}\text { No. of dead } \\
\text { nodes }\end{array}$ & Proposed & LEACH & $\begin{array}{c}\text { I- } \\
\text { LEACH }\end{array}$ & LEACH & I-LEACH \\
\hline FND & 1797 & 1201 & 1561 & 49.63 & 15.12 \\
\hline $10 \%$ & 2271 & 1655 & 2042 & 37.22 & 11.21 \\
\hline $25 \%$ & 2554 & 2219 & 2474 & 15.10 & 3.23 \\
\hline HND & 3351 & 3245 & 3208 & 3.27 & 4.46 \\
\hline $75 \%$ & 4148 & 3979 & 3727 & 4.25 & 11.30 \\
\hline $90 \%$ & 4550 & 4303 & 4229 & 5.74 & 7.59 \\
\hline \multicolumn{7}{|c|}{ BS at (100,250), Area=200x200, Node=400, P=0.05 } \\
\hline
\end{tabular}

Figures (2)-(9), demonstrate the metrics of network lifetime, throughput, energy consumption, and residual energy, in both simulation scenarios. Obviously, the outcomes confirmed that the proposed protocol outperforms LEACH and Improved-LEACH protocols in these metrics.

The rationale behind the enhancement in performance is that, the proposed protocol uses an efficient method for cluster head selection and distributes cluster heads through the network space evenly. Furthermore, the proposed protocol highly reduces the overhead of control messages in the setup phase by making data transmission period as long as possible.

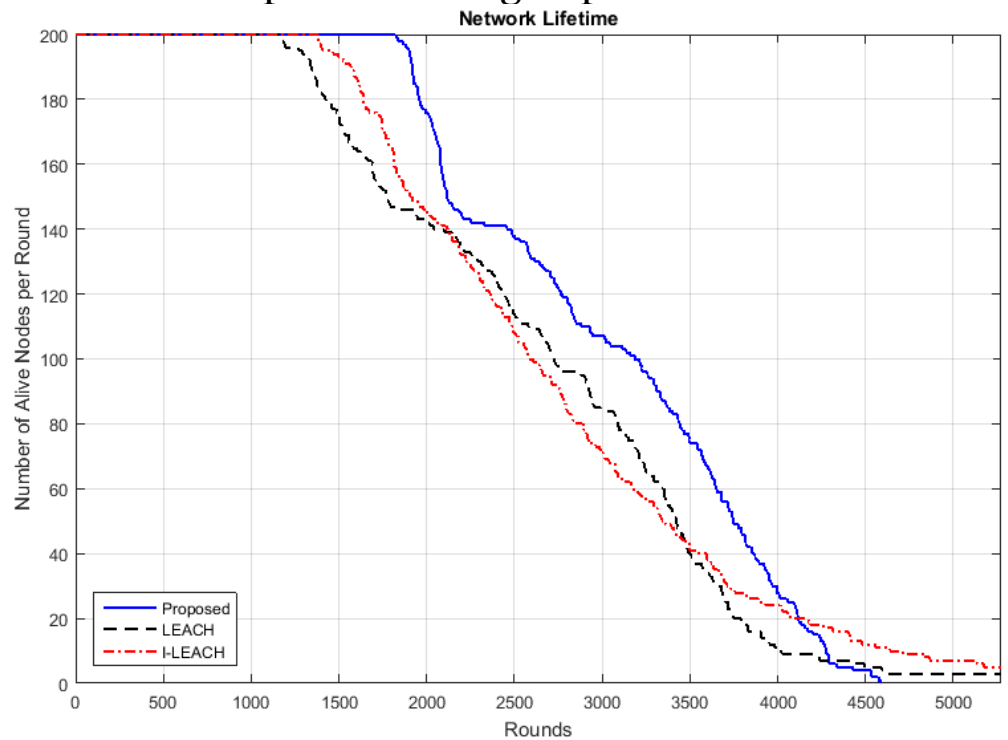

Figure-4: Network Lifetime for Protocols in Scenario-1 


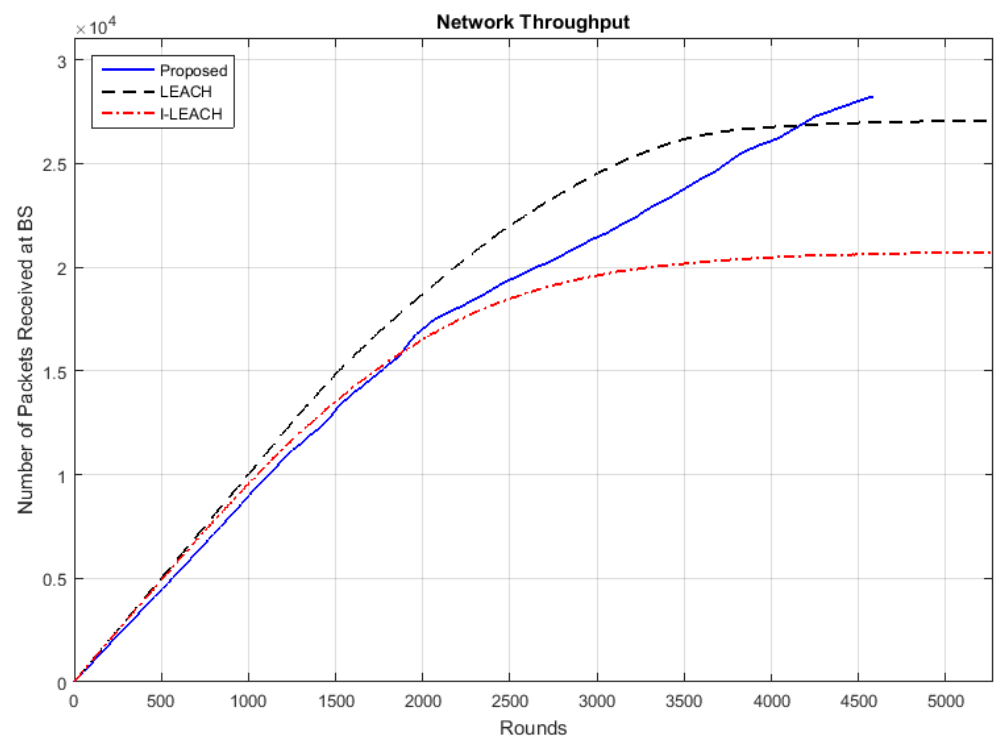

Figure-5: Network Throughput for Protocols in Scenario-1

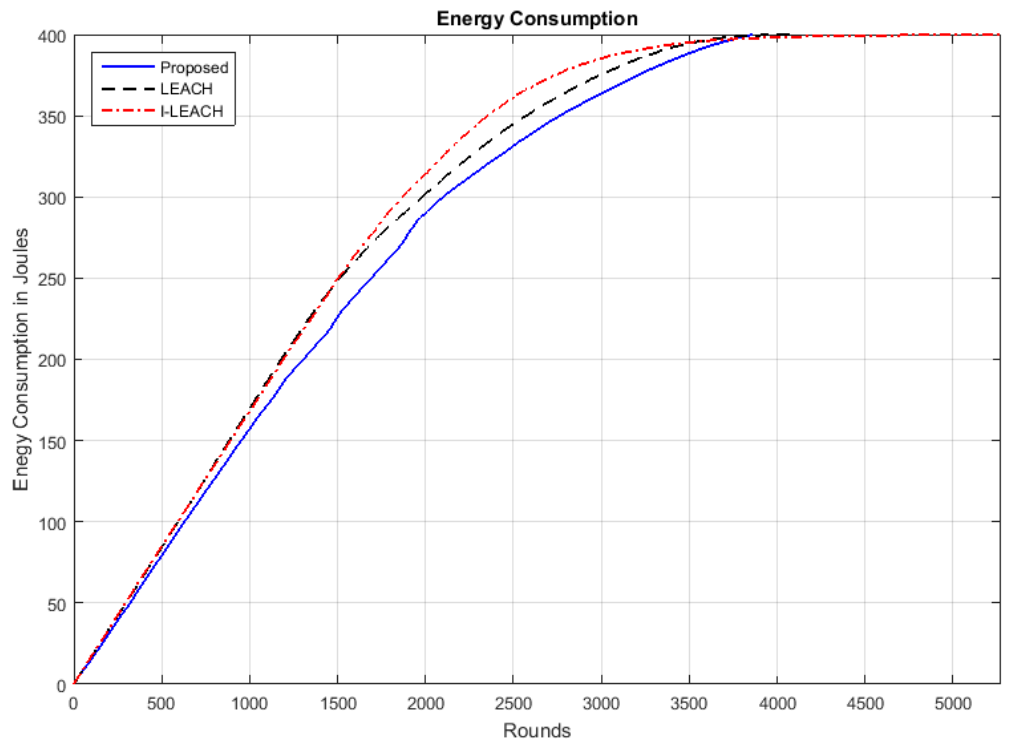

Figure-6: Energy Consumption for Protocols in Scenario-1

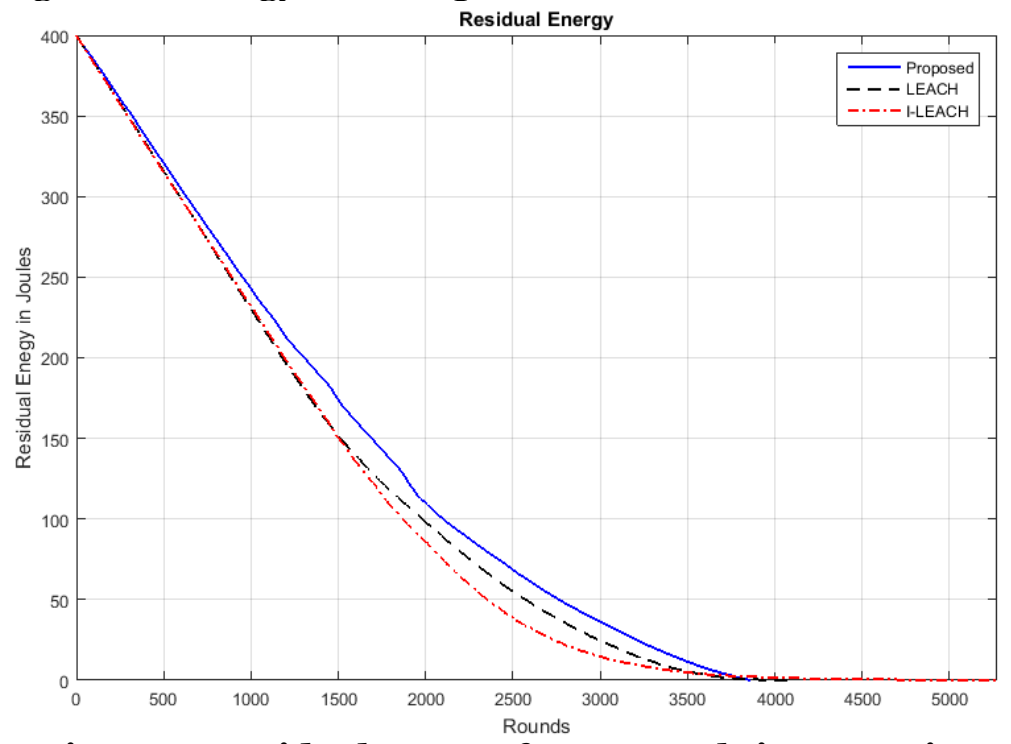

Figure-7: Residual Energy for Protocols in Scenario-1 


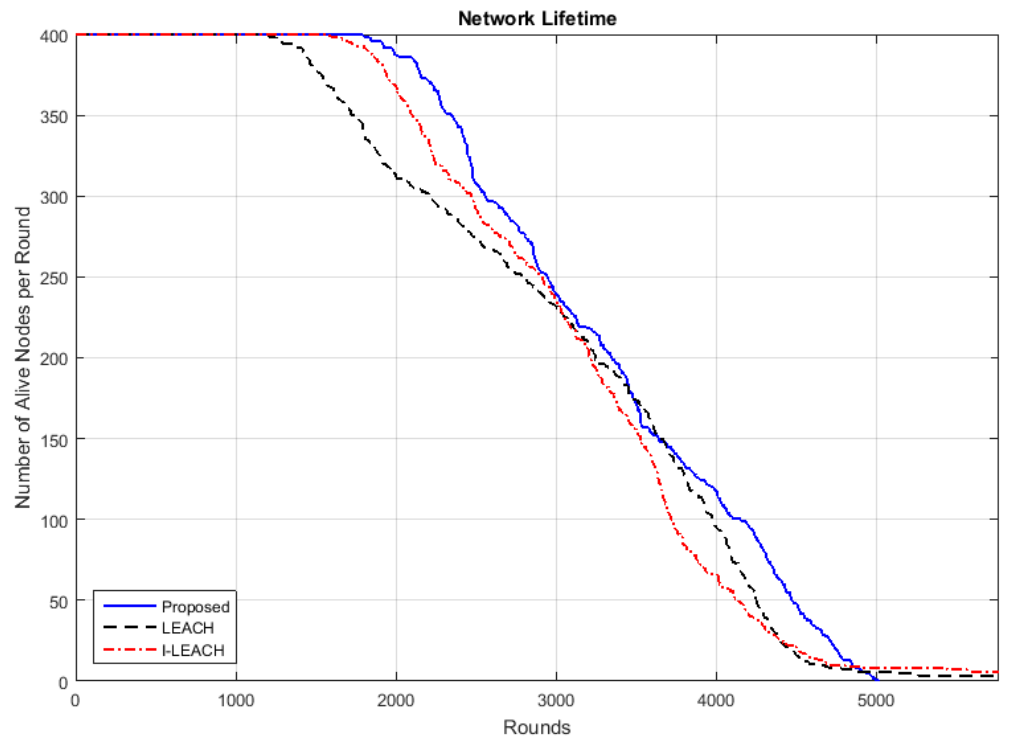

Figure-8: Network Lifetime for Protocols in Scenario-2

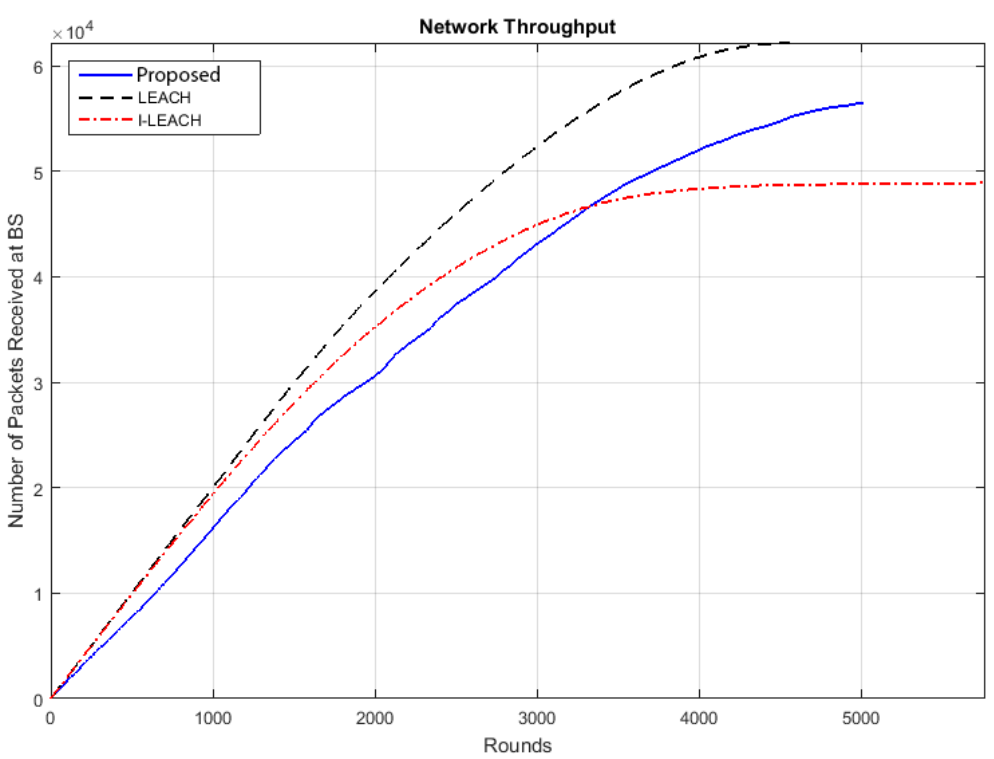

Figure-9: Network Throughput for Protocols in Scenario-2 


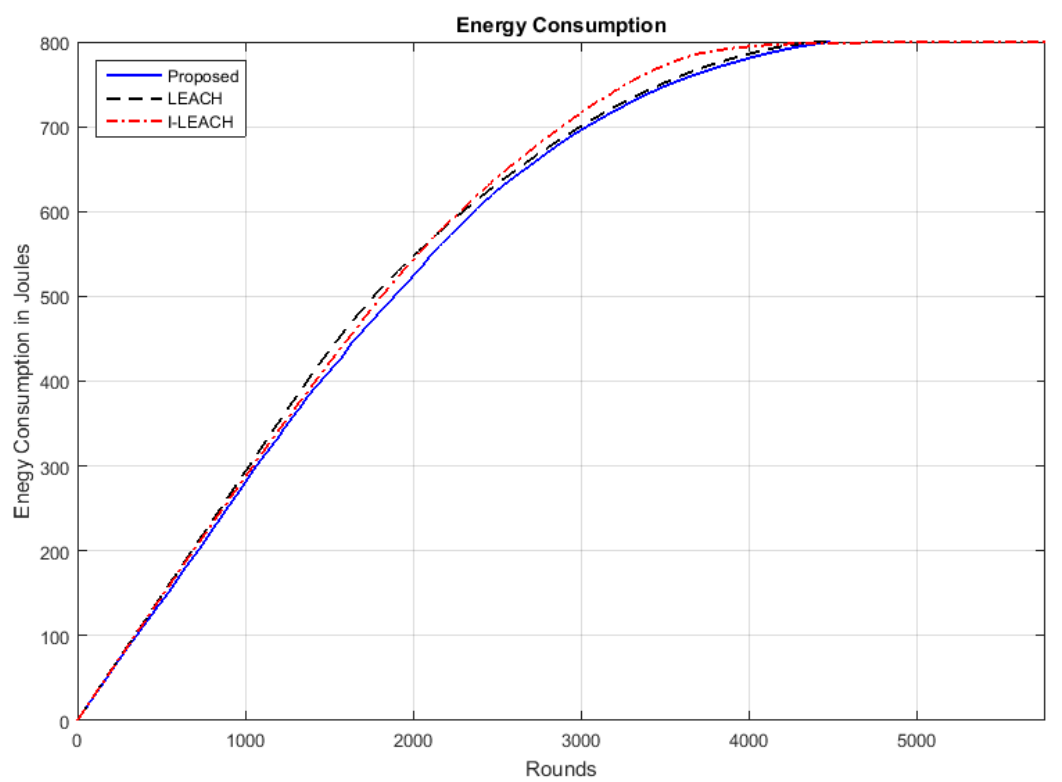

Figure-10: Energy Consumption for Protocols in Scenario-2

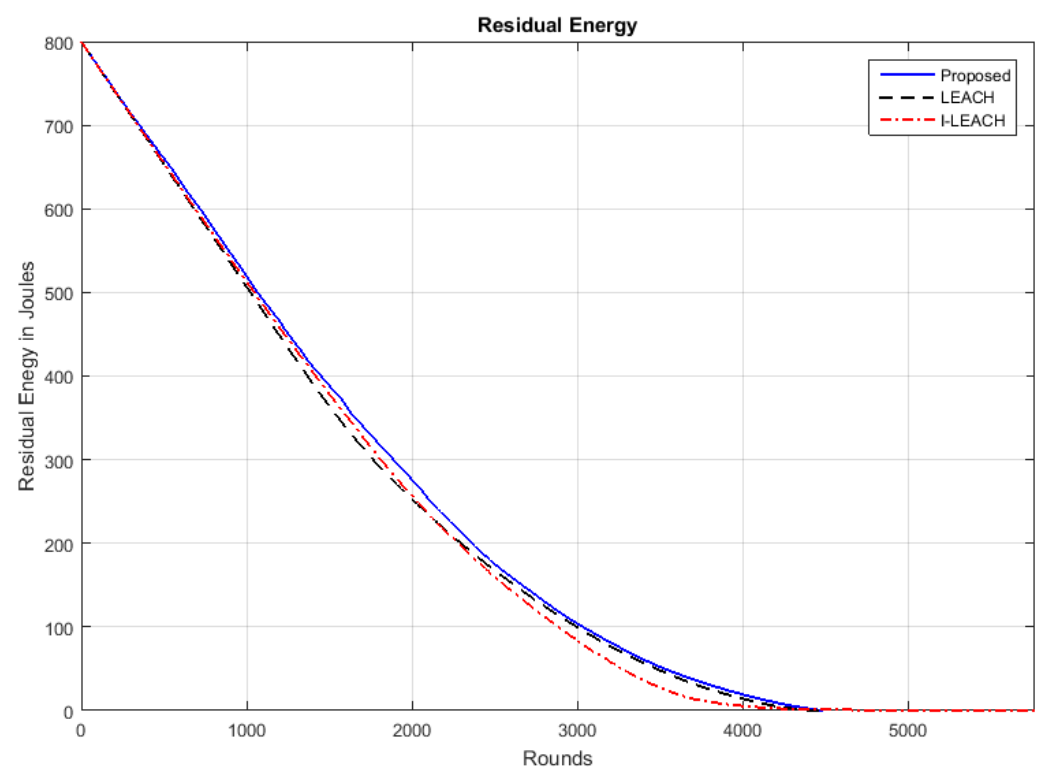

Figure-11: Residual Energy for Protocols in Scenario-2

\section{Conclusion}

The paper deals with energy efficiency issue in WSNs and suggested an energy-efficient cluster-based routing protocol to make energy dissipation more efficient. According to the results of conducted simulation, the performance of the proposed protocol was improved regarding metrics: the network lifetime, network throughput, energy consumption and residual energy. Also, this study shows the effect of cluster heads number, distribution of cluster heads, sizes of clusters, and overhead of control messages on the network performance and especially on the network lifespan. Eventually, a multi-hop routing protocol based on the current work will be suggested as a next work. 


\section{References}

[1] I. F. Akyildiz, W. Su, Y. Sankarasubramaniam, E. Cayirci, A survey on sensor networks (2002).

[2] A. A. Abbasi, A survey on clustering algorithms for wireless sensor networks, Comput. Commun 30 (2007) 2826-2841.

[3] S. P. Singh, S. C. Sharma, Cluster based routing algorithms for wireless sensor networks (2014).

[4] X. Liu, A survey on clustering routing protocols in wireless sensor networks, Sensors (2012) 11113- 11153.

[5] M. Radi, B. Dezfouli, K. A. Bakar, M. Lee, Multipath routing in wireless sensor networks: Survey and research challenges, 2012, pp. 650-685.

[6] M. M. Warrier, A. Kumar, Energy efficient routing in wireless sensor networks : A survey (2016).

[7] D. Wajgi, Load balancing based approach to improve lifetime of wireless sensor network, Int. J. Wirel. Mob. Networks 4 (4) (2012) 155-167.

[8] W. R. Heinzelman, A. Chandrakasan, H. Balakrishnan, Energy-efficient communication protocol for wireless microsensor networks, Proc. 33rd Annu. Hawaii Int. Conf. Syst. Sci., vol. o, no. c o (2000) 3005-3014.

[9] M. Ye, C. Li, G. Chen, J. Wu, Eecs: An energy efficient clustering scheme in wireless sensor networks, Int. Performance, Comput. Commun. Conf (2005) 535-54024th IEEE.

[10] C. Li, M. Ye, undefined G. Chen, An energy-efficient unequal clustering mechanism for wireless sensor networks, 2005.

[11] S. Lee, J. Lee, H. Sin, S. Yoo, S. Lee, J. Lee, Y. Lee, S. Kim, An energy-efficient distributed unequal clustering protocol for wireless sensor networks, World Academy of Science, Engineering and Technology (2008) 443-447.

[12] P. Ren, J. Qian, L. Li, Z. Zhao, X. Li, Unequal clustering scheme based leach for wireless sensor networks, 2010, pp. 90-93, proc. - 4th Int. Conf. Genet. Evol. Comput. ICGEC.

[13] G. V. Selvi, R. Manoharan, A survey of energy efficient unequal clustering algorithms for wireless sensor networks, International J. Comput. Appl 79 (1) (2013) 1-4.

[14] S. Arjunan, P. Sujatha, A survey on unequal clustering protocols in wireless sensor networks, Journal of King Saud University - Computer and Information Sciences.

يمثل ترشيد استهلاك الطاقة في شبكات المتحس اللاسلكي مسألة اساسية لكون عمر الثبكة يعتمد كليا

على الطاقة المتوفرة عادة في اجزة المتحسسات. في هذه المقالة تم اقتر اح بروتوكو لا للارسال مبني على اساس

العنقدة غير المتساوية حيث يأخذ بنظر الاعتبار منغييرات الطاقة و المسافة و الكثافة في تحديد راس كل مجموعة

(عنقود). وكذلك يكون حجم العناقيد غير منساو وفقا لمتغرات المسافة و الطاقة والكثافة. مضافا الى ان رؤوس

العناقيد لا يتم تغييرها في كل دورة ما لم يصل مستوى الطاقة فيها الى حد معين من الطاقة. ولقد بينت نتائج المحاكاة الى ان كفاءة البروتوكول المقترح تحقق تحسسنا في ترشيد الطاقة.

الكلمات المفتاحية: شبكات المتحسس اللاسلكي، القفزة المفردة، تعدد القفزات، العنقدة غير المتساوية، بروتوكول الازرسال 